\title{
Persistence and Loss of Cultural Values of Tiriki Sacred Groves in Hamisi District, Kenya: Implications For Management (RH: Cultural Values of Tiriki Sacred Groves)
}

\author{
Fredrick Nyongesa Kassilly* and Harrison Mugatsia Tsingalia** \\ Department of Biological Sciences, Masinde Muliro University of Science and Technology, \\ P.O Box 190, Kakamega 50100, Kenya \\ *Telephone: +254-056-3175, *Fax: +254-056-31053,*E-mail:nkasili@yahoo.com, \\ **E-mail:mugatsi2005@yahoo.com
}

KEYWORDS Biodiversity. Cultural Value. Ecotourism. Herbal Medicine. Sacred Groves

\begin{abstract}
Negligence and desecration observed among Tiriki sacred groves during causal visits by the authors in January 2007 was associated with their loss of cultural values and protection among local people. Household interviews were held with 65 randomly selected key informants (51 males, 14 females) from all (6) locations of Hamisi district, Kenya, between March and August 2007. The study objective was to determine the persistence and loss of traditional cultural values of the groves among local people plus respective causes for loss of the individual cultural values. Of the 10 traditional values named, the most dominant was as sources of herbal medicine (100\%) and as sites for boys' circumcision $(100 \%)$. The least dominant were as sources of food $(13.85 \%)$ and materials for house construction( $21.54 \%)$. Persistence was highest with their value as sources of herbal medicine $(100 \%)$ and lowest as burial sites for community heroes $(0.00 \%)$ and as sites for special prayers $(4.17 \%)$. Break-down in the socio-cultural fabric of the Tiriki community due to the influence of modern religion, education and government regulations were responsible for loss of cultural values and indigenous knowledge associated with sacred groves among local people. Sustainable preservation of the sacred groves requires strategic government intervention with an appropriate institutional framework that empowers local people to effectively manage and benefit from them. Emphasis is on enterprises that combine biodiversity conservation with poverty eradication as outlined by the Millennium Development Goals. Establishment of local, regional and global partnerships towards this end is encouraged.
\end{abstract}

\section{INTRODUCTION}

Sacred groves are special forest areas imbued with super natural powers and commonly comprise sites for ritual, initiation and other special functions and ceremonies (Abbi 1990; Posey 1998). Available literature reveals that sacred groves are a global phenomenon (Gupta 1980) with high similarity in the cultural and ecological dimensions of their management in Africa ( Campbell 2004), Asia (Malhotra et al. 2001), Europe (Lucas 1968), Latin America (Acha 2003) and Australia (Elias 2003). Wherever they occur, access to sacred groves is highly restricted, resulting in a hands-off approach regarding people's interaction with their biological wealth. Taboo associations attached to sacred groves

*Corresponding Author:

Fredrick Nyongesa Kassilly,

Department of Biological Sciences, Masinde Muliro

University of Science and Technology, P.O Box 190,

Kakamega-50100, Kenya

Telephone: +254-056-3175

Fax: +254-056-31053

E-mail: nkasili@yahoo.com have played an important role in their protection by indigenous and local people. Their continued survival has in effect offered protection to the biological life therein, turning them into biodiversity reservoirs.

Among the international organizations at the vanguard of the recognition and protection of sacred groves is the United Nations Educational, Scientific and Cultural Organization (UNESCO) which has at its disposal two global instruments to protect the world's environmental sites: the Programme on Man and the Biosphere (MAB) and the World Heritage Convention (Schaaf 2003). Both the UNESCO-MAB biosphere reserve concept (UNESCO 1996) and the World Heritage Convention (UNESCO 1972) clearly recognize the importance of sacred sites/groves and place them into the context of sustainable development. Through its global network UNESCO continues to play a leading role in expanding human capacity to conserve and benefit from biodiversity through protection of sacred sites and groves.

The Tiriki sacred groves in Kenya represent remains of a rainforest of which much has been lost. In spite of their long history, these sacred 
groves have suffered neglect by researchers and hardly any study has been undertaken to document their rich biological wealth. Research on forests in Western Kenya (Cords 1987; Emmerton 1992; Opole 1991, 1992; Ipara 2002) has largely focused on Kakamega forest, effectively ignoring the neighboring Tiriki sacred groves. Through time, the groves have owed their existence directly to the cultural belief systems and practices of the Tiriki people, who maintained traditional institutions that regulated access to, and use of, their resources. The historical role of the sacred groves in the cultural life of the Tiriki people can not be overemphasized. A council of elders from the local community oversees their preservation under supervision of the Kenya government.

In many cases, sacred groves have been accompanied by access restrictions, with the result they have served as reservoirs of biological diversity, preserving unique and/or rare plants and animal species. Consequently, increasing attention is being paid to their potential as a tool and model for biodiversity conservation globally. In 2002, at the World Summit on Sustainable Development (WSSD) in Johannesburg, South Africa, countries of the world committed themselves to reverse the rate of biodiversity loss by the year 2010. What is often overlooked, however, is the second part of the global 2010 target wording which provides the reason for addressing biodiversity loss: "as a contribution to poverty alleviation and to the benefit of all life on earth". Hence, as biodiversity reservoirs, sacred groves have a role to play in improving human livelihoods. Preservation of Tiriki sacred groves and their biological wealth will contribute to Kenya's endeavor to achieve the global 2010 target.

Informal visits to the sacred groves by the authors in January 2007 revealed illegal logging as an important threat to their continued survival. Special ceremonial sites within the groves commonly referred to as "kavunyonje" had been neglected and/or desecrated. Local community protection of the sacred groves was evidently waning. It was hypothesized that the decline in effective protection of the sacred groves was because their cultural roles and values in local people's lives had diminished, and so had the need for their preservation.

This study was undertaken to identify:

(i) The traditional cultural values for which the
Tiriki people conserved the sacred groves.

(ii) The cultural values in (i) above which persist today and those which have been lost.

(iii) Societal attributes responsible for the persistence and loss in (ii) above.

\section{Study Area}

The study was conducted in Hamisi district which consists of 2 divisions namely Tiriki West which comprises 4 locations having 20 sacred groves with a total area of 22.8 ha and Tiriki East which comprises 2 locations having 16 sacred groves with a total area of 26.9 ha. The area has an average altitude of $1500 \mathrm{~m}$ and a mean annual precipitation of $2000 \mathrm{~mm}$. It is occupied by the Tiriki people who are a sub-tribe of the larger Luhya community of Western Kenya.

\section{METHODS}

Methods used included participatory observation and household structured interviews and discussions with key informants between March and September, 2007. The study targeted elderly respondents aged $60+$ years who, due to advanced age had knowledge of the traditional roles of the sacred groves in the culture of the Tiriki. Both qualitative and quantitative data were collected.

The interview was conducted in a language best understood by individual respondents i.e. English, Kiswahili or Kiluhya. Respondents from each sub-location were randomly selected from names of elderly residents provided by the Assistant Chief responsible for the respective sub-location. Only natives with uninterrupted residence within their respective sub-locations were interviewed. To ensure equal spatial distribution of respondents, sampling was geographically stratified by selecting respondents throughout each sub-location. Each of the two researchers consistently asked the same particular questions, in the same order to all the respondents.

For each cultural value named, researchers marked "Not Important" if such a value was reportedly lost, "Important" if it was reportedly partially lost and "Very Important" if it was reportedly still in vogue. Persistence and loss of cultural values plus their respective possible explanations were summarized for each respondent and later compiled for the whole group. Data analysis involved descriptive statistics. 


\section{RESULTS}

A total of 65 respondents (41 males, 24 females) were interviewed. Ten (10) traditional cultural values of Tiriki sacred groves were mentioned (Table 1). Predominance varied among

Table 1: Percent mention (dominance) of cultural values of Tiriki sacred groves

\begin{tabular}{lrr}
\hline Cultural value & $\begin{array}{c}\text { Fre- } \\
\text { quency }\end{array}$ & $\begin{array}{c}\text { Percent } \\
\text { mention } \\
\text { (predomi- } \\
\text { nance) }\end{array}$ \\
\hline Sites for circumcision of boys & 65 & 100.00 \\
Sites for rituals/cleansing ceremonies & 52 & 80.00 \\
Sanctuary for sacred plants & 44 & 67.69 \\
Sites for special prayers & 48 & 73.84 \\
Sources of herbal medicine & 65 & 100.00 \\
Sources of food & 9 & 13.85 \\
Sources of construction materials & 14 & 21.54 \\
Burial sites for heroes & 44 & 67.69 \\
Sites for cultural teachings & 60 & 92.31 \\
Sanctuary for sacred animals & 53 & 81.54 \\
\hline
\end{tabular}

Table 2: Persistence and Loss of cultural values of Tiriki sacred groves

\begin{tabular}{|c|c|c|c|}
\hline Cultural value & $\begin{array}{l}\text { Loss } \\
(\%)\end{array}$ & $\begin{array}{l}\text { Persis- } \\
\text { tence } \\
\text { Partially } \\
\text { lost/in } \\
\text { vogue) } \\
(\%)\end{array}$ & $\begin{array}{l}\text { Not } \\
\text { sure } \\
(\%)\end{array}$ \\
\hline $\begin{array}{l}\text { Sites for circumcision } \\
\text { of boys }\end{array}$ & 80.00 & 20.00 & 0.00 \\
\hline $\begin{array}{l}\text { Sites for rituals/ } \\
\text { cleansing ceremonies }\end{array}$ & 86.55 & 9.61 & 3.84 \\
\hline Sanctuary for sacred plants & 81.82 & 13.64 & 4.54 \\
\hline Sites for special prayers & 91.66 & 4.17 & 4.17 \\
\hline Sources of herbal medicine & 0.00 & 100.00 & 0.00 \\
\hline Sources of food & 88.89 & 11.11 & 0.00 \\
\hline $\begin{array}{l}\text { Sources of construction } \\
\text { materials }\end{array}$ & 14.29 & 57.14 & 28.57 \\
\hline Burial sites for heroes & 100.00 & 0.00 & 0.00 \\
\hline Sites for cultural teachings & 71.68 & 26.66 & 1.66 \\
\hline Sanctuary for sacred animals & 79.88 & 5.03 & 15.09 \\
\hline
\end{tabular}

the different values. The most dominant included their use as sites for circumcision of boys (100\%), sources of herbal medicine $(100 \%)$ and as sites for cultural teaching of candidates during initiation $(92.31 \%)$. The least dominant included their use as sources of construction materials $(21.54 \%)$ and food $(13.85 \%)$.

Table 2 is a summary of results on persistence and loss of traditional cultural values of sacred groves among local communities. The most persistent were values associated with the groves acting as sources of herbal medicine (100\%) and construction materials $(57.14 \%)$. The least persistent included their use as burial sites for heroes $(0.00 \%)$ and sanctuaries for sacred animals $(5.03 \%)$. Table 3 summarizes societal attributes that have contributed to the reported loss of cultural values of sacred groves. Loss of cultural values of the sacred groves among local people was associated with the influence of modern religion, education, government regulations and general modern lifestyles.

\section{DISCUSSION}

The study sample comprised more male than female respondents because it was restricted to senior citizens who had uninterrupted residence within respective sub-locations. For females, this meant those who grew up and married within their sub-locations of birth. Not many females met this requirement because of relocating to new places of residence upon marriage, hence the gender disparity among respondents. The reasoning behind the requirement was that female respondents who became residents of their respective sub-locations as a result of marriage (in adult age) were unlikely to competently trace trends in persistence or loss of cultural values of sacred groves in their present sub-locations. Furthermore, some of them don't belong to the Tiriki

Table 3: Societal attributes impacting on cultural values of Tiriki sacred groves among local communities

\begin{tabular}{ll}
\hline Cultural value & Societal attribute \\
\hline Sites for circumcision of boys & Modern religion, culture, and education \\
Sites for rituals/cleansing ceremonies & Modern religion, culture and lifestyles \\
Sanctuary for sacred plants & Modern religion and culture \\
Sites for special prayers & Modern religion and government regulations \\
Sources of herbal medicine & Efficacy, availability and affordability of herbal medicine \\
Sources of food & Modern culture and lifestyle \\
Sources of construction materials & Government regulations and modern material culture \\
Burial sites for heroes & Government regulations \\
Sites for cultural teachings & Modern culture, lifestyles and religion \\
Sanctuary for sacred animals & Modern religion and culture \\
\hline
\end{tabular}


sub-tribe and lack adequate knowledge on the history of the Tiriki sacred groves.

Differences in dominance of traditional cultural values of sacred groves reported in this study reflects regional differences in cultural practices associated with them among residents of Hamisi district. This translates to spatial differences in people's cultural linkages with the groves resulting in sporadic persistence or loss of values within the study area.

Results reveal that the culture of the Tiriki people, like other human cultures, changes and is not immutable. With time, new social, religious, cultural, economic and political circumstances have impacted on Tiriki culture and gradually changed it as reflected by their current relations with the sacred groves. This is the reason some purposes for which the Tiriki people originally wanted the sacred groves preserved have gradually become obsolete which explains the neglect and desecration which most of the sacred groves have suffered.

Societal attributes responsible for the cultural estrangement of the Tiriki people from their sacred groves reported in this study are similar to those for India (Vartak and Gadgil 1981) and Ghana (Posey 1998). Modern religion and education are important cultural defoliants among traditional communities in Kenya which, coupled with the government program of modernization of the rural sector are responsible for abandonment of traditional cultural practices and lifestyles (Kassilly 2000). Study findings corroborate observations by Mbiti (1969) that the Luhya of Western Kenya originally had very strong links with nature which were however systematically severed with introduction of modern religion and education upon the country's colonization. There is increasing concern among Kenyan conservationists over the loss of traditional wisdom and practices by traditional communities as they embrace Western conservation ethics and value systems most of which are inimical to African cultures that defined their relations with nature. This, coupled with marginalization of traditional institutions such as councils of elders whose roles in natural resource conservation have been usurped by government departments and agencies has expedited loss of indigenous knowledge and cultural values of sacred groves among local people.

Discussions with respondents revealed that the current disregard for access sanctions to the Tiriki sacred groves is responsible for over- harvesting of Antiaris toxicaria, once considered a sacred tree among the Tiriki and Markhamia lutea which was a special tree for house construction and of vegetable plants including Erythrococca atrovirensis and fruits like Maesopsis eminii, Atrosersalisia cerasifera and Trilepisium madagascariensis. The same fate has befallen Mondia whytei, a popular medicinal herb for treatment of stomach ailments in Western Kenya.

Threats to effective conservation of Tiriki sacred groves identified in this study compare with those facing conservation of sacred groves elsewhere in the world as reported by Schaaf (2003). The Kenya government should secure and maintain the support and involvement of local people in the conservation of Tiriki sacred groves and their biodiversity in its bid to attain the Convention on Biological Diversity (CBD) target by 2010 and the Millennium Development Goals by 2015 (MA 2005). Community participation in conservation of former traditional forests (currently gazetted) including sacred groves should underpin government policy and efforts to protect them. A review by Roe et al.( 2006) showing that local management of biodiversity can contribute to human well-being both directly ( for example, through incomeearning opportunities, local employment, and increased security of resource access) and indirectly (through conservation practice and the impact this has on ecosystem services) is of practical relevance to the case of Tiriki sacred groves and their management.

\section{CONCLUSION AND RECOMMENDATIONS}

Study findings lead to the conclusion that cultural values and traditional belief systems of the Tiriki people alone are no longer adequate in securing a future for the sacred groves in Hamisi District. Cultural evolution has made local people abandon sentiments and acts that at one time ensured preservation of the sacred groves. As the Tiriki people adapt to the social, cultural, political and economic miasma of a modern Kenya, their cultural links with the sacred groves have had to suffer. Restoration of close links between local people and the sacred groves requires that a new set of incentives, values and benefits be developed to make people cultivate the need for their preservation.

The study recommends for strategic govern- 
ment intervention with a supportive institutional framework that improves the capacity of the local community to sustainably manage and benefit from the sacred groves. Conservation agenda for the groves should seek to promote ethno-forestry by commercializing their marketable products including herbs, firewood, construction materials and mushrooms for the benefit of communities and not individuals. Furthermore, the government needs to support community initiatives that preserve and market the sacred groves as cultural landscapes for promotion of ecotourism in Western Kenya. Collaboration with local, regional and international partners in meeting this goal is encouraged. Development of a sense of proprietorship among local people over the sacred groves will ensure their sustainable preservation as biodiversity enclaves.

\section{REFERENCES}

Acha MO 2003.Safeguarding Huichol and Seri Natural and Cultural Heritage in Mexico. Paper presented at the International Workshop on The Importance of Sacred Natural Sites for Biodiversity Conservation in Kunming and Xishuangbanna Biosphere Reserve, People's Republic of China, February 17 to 20, 2003.

Abbi WD 1990. Useful plants of Ghana: West African Uses of Wild and Cultivated Plants. London: Intermediate Technology Publications.

Campbell MO 2004. Traditional forest protection and woodlots in the coastal savannah of Ghana. Environmental Conservation, 31: 225-232.

Cords M 1987. Mixed-species association of Cercopithecus monkeys in the Kakamega Forest, Kenya. University of California Publications in Zoology, 117:109-133.

Elias D 2003. Sacred Sites in the Tanami Desert, Central Australia. Paper presented at the International Workshop on The Importance of Sacred Natural Sites for Biodiversity Conservation in Kunming and Xishuagbanna Biosphere Reserve, People's Republic of China, February 17 to 20, 2003.

Emmerton L 1992. Summary of Findings on Forest Utilization in Kakamega Forest. Kenya Indigenous Forest Conservation Programme Report, Nairobi: Kenya.

Gupta SS 1980. Sacred Trees Across Cultures and Nations. Calcutta: Indian Publications.

Ipara H 2000. Towards cultural tourism development around Kakamega Forest Reserve in Western Kenya. Paper presented in a conference on Tourism and Leisure Education, Mombasa, Kenya, December 13 to $16,2000$.

Kassilly FN 2000. Human Dimensions of Wildlife Resources Management in Kenya: A Study of People-wildlife Relations Around Two Conservation Areas. Dr rer nat Thesis (Unpublished), Vienna: University of Natural Resources and Applied Life Sciences.

Lucas AT 1968. The sacred trees of Ireland. Journal of the Cork Historical and Archeological Society, 68: 16-54.

Millennium Ecosystem Assessment 2005. Ecosystems and Human Well-Being: Biodiversity Synthesis. Washington DC: Island Press.

Malhotra KC, Ghokhale Y, Chatterjee S, Srivastava S 2001. Cultural and Ecological Dimensions of Sacred Groves in India. New Delhi: INSA.

Mbiti J 1969. African Religions and Philosophy. Nairobi: East African Educational Publishers Ltd.

Opole M 1991.User trends and attitudes to management of the Kakamega Forest Reserve. Kenya Indigenous Forest Conservation Programme Report, Nairobi: Kenya.

Opole M 1992. Report on community liaison activity in 3 village areas on the edge of Kakamega Forest Reserve. Kenya Indigenous Forest Conservation Programme Report, Nairobi: Kenya.

Posey D A 1998. Cultural and Spiritual Values of Biodiversity. London: Intermediate Technology Publications.

Roe D, Jones B, Bond I, Bhatt S 2006. Local Actions, Global Aspirations: The role of community conservation in achieving international goals for environment and development. IIED Natural Resource Issues Paper No. 6, London: International Institute for Environment and Development.

Schaaf T 2003. UNESCO's Experience with the Protection of Sacred Natural Sites for Biodiversity Conservation. Paper presented in the International Workshop on The Importance of Sacred Natural Sites for Biodiversity Conservation in Kunming and Xishuangbanna Biosphere Reserve, People's Republic of China, February 17 to 20, 2003.

UNESCO 1972. Report of the Convention Concerning the Protection of the World's Cultural and Natural Heritage. Paris: Unesco.

UNESCO 1996. Biosphere Reserves: the Servile Strategy and the Statutory Framework of the World Network. Paris: Unesco

Vartak V D, Gadgil M 1981. Studies on sacred groves along the Western Ghats from Maharashtra and Goa. Role of beliefs and folklore. In: SK Jain (Ed.): Glimpses of Indian Ethnobotany. Delhi: Oxford \& IBH Publications, pp. 272-278. 